\title{
VIOLÊNCIA: A CATEGORIZAÇÃO DE HOMENS E MULHERES CEARENSES
}

\author{
Kaline Girão Jamison ${ }^{1}$ \\ Letícia Adriana Pires Ferreira dos Santos ${ }^{2}$
}

\begin{abstract}
RESUMO
A violência pode ser considerada um dos conceitos mais evasivos e difíceis de serem definidos dentro da área das ciências sociais e percebem-se poucas discussões do ponto de vista da linguagem. Em nosso trabalho, verificamos o modo de estruturação da categoria VIOLÊNCIA, assim como as escalas de prototipicidade a partir de exemplares apontados por homens e mulheres cearenses. Assim, baseando-nos na Teoria de Categorização de Rosch (1975) e na Teoria dos protótipos de Lakoff (1987), citados por Macedo; Feltes; Farias (2008), tivemos o objetivo de verificar se havia diferenças significativas entre as escalas de prototipicidade da categoria que haviam sido apontadas em dois grupos distintos: de homens e de mulheres cearenses. Adotamos, como referencial teórico, os postulados de Rosch (1975), Lakoff (1987) apud Macedo; Feltes; Farias (2008),, Jacob e Shaw (1998) entre outros. Constatamos que os exemplares citados por homens e mulheres, nos questionários para definir a categoria VIOLÊNCIA, se apresentaram de forma diferenciada, confirmando uma de nossas hipóteses: o homem cearense é tido como "cabra de peste", homem macho, que torna evidente mais a violência física do que a violência psicológica. Os resultados revelaram que enquanto no grupo de homens o exemplar mais saliente constituiu o submodelo metonímico de FORÇA FíSICA, o feminino apresentou exemplares que se enquadravam no submodelo metonímico de FORÇA PSICOLÓGICA.
\end{abstract}

Palavras-chave: Violência. Categorização. Prototipicidade. Gêneros. 


\section{INTRODUÇÃO}

A linguagem é uma forma de interagir no mundo, os nossos conhecimentos são adquiridos através das nossas vivências; somos, portanto, atores sociais, camaleões linguísticos. Sendo assim, defendemos que não há um único conceito, uma única forma de categorizar as coisas que nos rodeiam. Pensando nisso, tivemos como objetivo neste trabalho, verificar se havia diferenças significativas no modo de estruturação da categoria VIOLÊNCIA entre homens e mulheres cearenses.

Com tal objetivo em mente, apresentamos aqui, os pressupostos teóricometodológicos que guiaram as análises qualitativo-quantitativas conduzidas a partir dos dados colhidos e uma amostra dessas análises. Vale mencionar que este trabalho contou com a colaboração dos alunos bolsistas do CNPq da Universidade Estadual do Ceará e do Centro Universitário Estácio, do Ceará, que aplicaram mais de cinco mil questionários entre os participantes voluntários da pesquisa.

Adotamos como base teórica a perspectiva da Teoria de Categorização de Rosch (1970) e dos protótipos de Lakoff (1987), que consideram que a experiência corpórea e a maneira como usamos os mecanismos imaginativos (metonímia e esquemas imagéticos), funcionam como elementos cruciais para a construção de categorias (LAKOFF, 1987). Situamo-nos, assim, em favor da cognição corporificada, pautados na visão atuacionista, da qual emerge o ser situado e cognoscente, que age e interage num mundo de percepções e ações, das quais emergem os significados.

$\mathrm{Na}$ seção seguinte, explicitaremos tais ideias teóricas, assim como resenharemos fenômenos da violência. Depois, mostraremos a contextualização da pesquisa, e em seguida, o método que utilizamos nas análises e uma amostra dessas análises. Por fim, fazemos algumas considerações e adicionamos as referências do trabalho.

\section{PRESSUPOSTOS TEÓRICOS}

\subsection{Violência}

Esta seção tem por objetivo resenhar o fenômeno violência, assim como alguns 
de seus aspectos mais importantes, direcionando-os à construção de conceitos e categorizações estabelecidos por homens e mulheres cearenses. Baseamo-nos no trabalho de Imbusch (2003), The concept of violence, que nos auxiliou a esboçar um percurso que esclarece as relações de homens e mulheres com os conceitos de violência. A primeira parte desta seção serve como pano de fundo para traçar os principais conceitos e protótipos mencionados pelos sujeitos da pesquisa.

Segundo Imbusch (2003), o conceito de violência consiste em um dos mais ardilosos e difíceis das ciências sociais. Com a crescente industrialização nos países ocidentais, a violência aumenta, tornando-se um dos temas mais estudados em artigos acadêmicos, livros e pesquisas. No entanto, ainda há controvérsias quanto à definição mais apropriada, diferenciação substantiva, valor sociopolítico e avaliação de violência (IMBUSCH, 2003). Nessa perspectiva, Imbusch acrescenta que pesquisas de opinião pública revelam que o conceito é extremamente difuso (KAASE; NEIDHARDT, 1990 apud IMBUSCH, 2003) variando de danos físicos e psicológicos a formas especificas de crime e comportamentos impolidos nas ruas ou nos esportes, inclusive discriminação social. Ou seja, nossa ideia do que seja violência está atrelada a uma noção seletiva e moldada direta e fortemente por interesses da mídia, a qual omite outros aspectos significantes do conceito de violência (IMBUSCH, 2003).

Ainda de acordo com Imbush (2003), há duas visões opostas do que é a origem da violência: de um lado, ela é relacionada à própria natureza humana, considerada imutável, e de outro, ela é agregada a condições sociais. Nesse sentido, Lawrence (1970, p. 31 apud IMBUSH, 2003, p. 14) explica:

Violência [...] envolve diversas questões e respostas conflitantes. Ela é uma
arbitrariedade ou uma necessidade? Uma inimiga à liberdade e à ordem
social ou um de seus pilares indispensáveis? Ela é meio racional ou
instrumento de autofrustração? É a resposta de um aprendizado pervertido
ou um instinto normal? A violência é uma forma patológica de
comportamento ou uma maneira voluntaria pela qual seus agentes
carregam toda responsabilidade? A sociedade pode prevenir sua ocorrência
ou precisamos renunciar a uma ordem que a inclua [...].

Por se tratar, portanto, de um conceito multifacetado, o fenômeno violência gera um leque de definições e explicações, cada uma com suas variações e demarcações, o que acaba gerando desacordo e divergência entre os conceitos de violência propostos.

O uso preciso do termo violência é dificultado por conotações que se 
sobrepõem parcialmente a conceitos semanticamente relacionados (agressão, conflito, poder etc.), mas que não são idênticos à violência. Imbush (2003) aponta, ainda, que uma terminologia mais precisa é dificultada por conceitos baseados em princípios coerentes e organizados, ou por repetições precipitadas (violência como guerra, como assassinato, etc.), que também não são idênticas à violência. Por exemplo, embora seja indispensável relacionar assassinato a um ato de violência, há uma delimitação do campo de visão do conceito, ao invés de uma diferenciação necessária (ALBRECHT; BACKLES; KÜHNEL, 2001 apud IMBUSCH, 2003, p. 14).

Conforme nos esclarecem Rauchfleisc, Brednich e Hartinger (1992; 1994 apud IMBUSCH, 2003, p. 14), a "violência é onipresente e um fenômeno acidental, cuja ubiquidade independe da área cultural”. Deparamo-nos com a violência em qualquer lugar, em grandes ou pequenas dimensões, em nível nacional ou internacional. Ela pode ocorrer em espaços sociais como violência apolítica em contextos variados (na família, escola, nas ruas, espaços públicos, contra idosos, crianças, mulheres, etc.), como crime violento (variando de homicídio a crime organizado), ou, ainda, como extensões de violência politicamente motivadas (terrorismo, torturas, perseguições) . O fato é que não há sociedade ou região no mundo que esteja livre da violência, mesmo com suas diferenças em formas e níveis de intensidade. Nesse prisma, Litke (2003 apud IMBUSCH, 2003, p. 14) complementa:

A violência é intrigante. Apesar de universalmente condenada, ela é
encontrada em todos os lugares. A maioria de nós é fascinado e
atemorizado por ela. A violência é um ingrediente fundamental do nosso
entretenimento (histórias infantis, literatura mundial, indústria de filmes) e
um traço essencial de muitas de nossas instituições. Em muitas partes do
mundo ela é notoriamente comum na vida familiar, nas relações religiosas e
na história política.

Devido, portanto, ao uso da palavra violência estar relacionado a distintos tipos e qualidades de fenômenos, servindo a diferentes propósitos e funções, vale destacar alguns de seus aspectos etimológicos. Por exemplo, em alemão, o termo Gewalt, significa violência. Segundo Neidhardt (apud IMBUSCH, 2003), as complicações do conceito violência na língua alemã são resultantes da polissemia do termo. De um lado, adquire significado puramente descritivo e isento de valores e de outro, está carregado de julgamentos. Contudo, a semântica desse conceito tem sofrido mudanças através do tempo, a ponto de sofrer sobreposições variáveis, dependentes do contexto. $\mathrm{O}$ autor esclarece que a ambiguidade do termo e de seu 
uso é decorrente das incongruências dos sistemas legais alemães e romanos, assim como de suas diferentes tradições conceituais e terminológicas.

Explicando melhor, em alemão, a palavra Gewalt não faz distinção entre violência pessoal direta (vis/violentia) e legítima violência institucional (potentia/potestas). Desse modo, apesar da clara distinção entre os conceitos de poder e de violência, percebemos que o termo Gewalt não distingue as duas raízes latinas, o que justifica a conexão feita entre os conceitos.

A origem da palavra Gewalt, em alemão, vem da raiz indo-europeia "val" (latim: valere), que era originalmente um verbo (giwaltan, waldan), cujo significado era "ter a habilidade de dispor de algo para demonstrar poder". No entanto, mais tarde, a palavra foi usada com uma conotação mais geral, no sentido de "ter força", "ter poder" e "controlar algo".

Assim, a palavra Gewalt foi colocada no mesmo grupo semântico de norma, governo e poder. O termo, no início, era usado como violentia (impetuosidade), substantivo usado em expressões compostas, paralelamente a outros termos em latim, como: potestas (autoridade), potentia (poder, habilidade força), auctoritas (influência), imperium, dominatus e maiestas (soberania territorial), vis (força, poder, violência) e facultas (possibilidade legítima de exercício do poder).

Interessante notar que o uso de Gewalt no contexto alemão passou por períodos de transição do final da Idade Média a Idade Moderna, incorporando quatro outras variantes do conceito (FABER et al., 1982 apud IMBUSH, 2003):

a) Gewalt era usado para denotar poder de instituições públicas conectadas ao sistema legal;

b) o termo era usado para fazer descrições livres de valores sobre autoridades territoriais, estatais e outros tipos de representantes;

c) o termo expressava relações de remoção de propriedade

d) e, por último, o termo serviu para caracterizar o uso de violência física no âmbito político, como também para descrever ações violentas individuais no senso de vis e violentia.

Por fim, foi com o surgimento do estado absoluto que a violência, no sentido de coação física, foi monopolizada e concentrada em mãos de pessoas e instituições, especificamente, designadas para esse propósito. E o uso de violência, fora desse contexto, era punido. Dessa forma, o conceito de violência foi perdendo gradualmente o sentido de potestas, mudando gradualmente para violentia. 
Inferimos, portanto, que assim como em gewalt, que não distingue violência pessoal direta (do latim vis/violentia) e violência institucional (do latim potestas), também usamos o termo violência em sentido amplo. Em expressões latinas, tais como: vis absoluta (violência física), vis compulsiva (violência moral), vis armata (força armada), vis minima (lei do menos esforço), vis major (força maior), Vis adjuvat aequum (a força protege a justiça) percebemos que conceitos como força e poder subjazem ao termo violência (vis). Na língua portuguesa, da mesma forma, podemos detectar algumas sobreposições semelhantes: e.g. A chuva de ontem foi violenta (no sentido de força), Praticou um atentado violento ao pudor (no sentido de força), etc.

\subsection{A categorização de homens e mulheres por meio de modelos metonímicos}

Uma razão importante, segundo Evans e Green (2006), pela qual a Linguística Cognitiva estuda a linguagem deve-se ao fato de ela refletir padrões do pensamento e propriedades fundamentais da mente humana. Dessa forma, nosso trabalho, cujo objetivo é pesquisar sobre a conceptualização de VIOLÊNCIA por pessoas de ambos os sexos, está inserido nos tópicos de interesse da Linguística Cognitiva. Baseamo-nos, assim, nos estudos da cognição corporificada (ou visão atuacionista), da qual emerge o ser situado e cognoscente, que age e interage no mundo de percepções e ações, de que emergem os significados. Dessa maneira, a Linguística Cognitiva possibilita o acesso a processos cognitivos, por meio de manifestações linguísticas.

De acordo com Lakoff (1987), ao discutir categorias conceituais, o pensamento é corporificado e baseado na percepção, no movimento corpóreo e na experiência física e social; o pensamento é imaginativo e se utiliza de metáforas, metonímias e imagens mentais, posto que é indiretamente corporificado e transcende à representação literal das coisas; o pensamento tem propriedades gestálticas e os conceitos adquirem uma estrutura mais geral; o pensamento tem uma estrutura ecológica e é mais do que, simplesmente, manipulação mecânica de símbolos abstratos; a estrutura conceitual pode ser descrita através de modelos cognitivos, que apresentam todas essas propriedades.

Segundo Johnson-Laird e Wason (1997, apud LIMA, 2007, 157), "qualquer cognitivista interessado em processamento de ideias tem que lidar com a questão de 
o que é conceito e de como ele é adquirido". Logo, nossa capacidade humana de conceptualização, conforme nos evidencia Lakoff (1987, p. 281), consiste em algumas habilidades, dentre elas: a) formarmos estruturas simbólicas relacionadas às experiências diárias; b) projetarmos metaforicamente a partir de estruturas do domínio físico ao abstrato; c) formarmos conceitos complexos e categorias gerais utilizando esquema de imagens; d) formularmos modelos cognitivos idealizados.

Desde o período aristotélico, já existia a preocupação com o ato de nomear coisas, definir e categorizar. Com as ciências cognitivas, porém, a noção de categorização sofreu mudanças, passando a ser vista não apenas como um processo individual, mas como o processo social e cultural de moldar a realidade a nosso redor. Segundo Lima $(2007,158)$,

Categorizar coisas é inerente aos seres humanos desde os primeiros momentos de vida, porque o cérebro dá forma às estruturas que espelham o ambiente externo em uma forma categorial. [...] Se nós não interagirmos com o meio ambiente, não teremos o que classificar; o ambiente influencia muito no modo como categorizamos a informação.

Dentro dessa perspectiva, propomo-nos a realizar uma análise, utilizando conceitos, categorizações e protótipos nos experimentos realizados com os sujeitos - de ambos os sexos - participantes do estudo. Esses modelos podem estabelecer efeitos de tipicidade, ao representar toda uma categoria, servindo como um "ponto de referência cognitiva", gerando normas e criando expectativas.

Nesse sentido, os modelos metonímicos são importantes para as nossas análises, pois, assim como a metáfora, a metonímia concebe uma coisa em termo de outra, tratando-se, nesse caso, da representação de todo um domínio por uma parte desse mesmo domínio, deixando claro que a base para essa projeção se encontra em um modelo proposicional ou de esquema de imagens. Logo, os modelos cognitivos metonímicos poderão nos ajudar a compreender quais são os conceitos sobre violência mais usados pelos sujeitos; como esses conceitos são construídos a partir de interações sociais - dinâmica social e cultural.

De acordo com Lakoff (1987), uma das maneiras de compreendermos uma categoria é via submodelos metonímicos, ou através de exemplos salientes de uma dada categoria. Esses modelos são responsáveis por representarem os exemplos memoráveis e mais conhecidos para representar uma categoria. Por exemplo, logo após algum acidente aéreo, as pessoas ficam relutantes em voar, por medo. Isso se 
dá por associarem o acidente à instabilidade e imprevisibilidade dos aviões, tendo em vista a notícia sobre o acidente a que assistiram na televisão em período recente. Desse modo, caracterizamos toda a categoria através de um exemplo saliente. No caso de nosso trabalho, percebemos que a categorização de VIOLÊNCIA também se dá por meio de exemplos salientes da categoria e por submodelos metonímicos. Ou seja, ao categorizarmos o conceito de VIOLÊNCIA, tendemos a pensar em um tipo ou em uma parte desse fenômeno para representar toda a categoria.

\section{CONTEXTUALIZAÇÃO DA PESQUISA}

Nosso trabalho foi realizado em Fortaleza, Ceará, com participantes de ambos os sexos, sendo o sexo dos informantes a variável controlada no estudo. $O$ questionário que serviu como instrumento de coleta de dados foi aplicado por alunos e bolsistas de projetos das autoras do estudo em questão. Vale acrescentar que além da participação desses alunos e bolsistas, houve também o envolvimento, tanto na coleta, quanto na tabulação e na análise de dados, dos participantes do grupo de estudo GELP-COLIN, coordenado pela professora Dra. Ana Cristina Pelosi. Foram coletados mais de cinco mil questionários, dos quais foram selecionados sessenta - trinta de respondentes masculinos e trinta, femininos, todos nascidos no Ceará. O contexto da pesquisa, portanto, foi a cidade de Fortaleza-Ceará, local de aplicação do experimento.

\section{MÉTODO}

O estudo respeitou às recomendações do Comitê de Ética quanto a pesquisas com seres humanos, garantindo confidencialidade, anonimato, utilização das informações coletadas sem prejuízo dos indivíduos e emprego das informações somente para os fins previstos na pesquisa.

O método adotado na investigação foi o hipotético-dedutivo. Esse método defende o surgimento de um problema antes de ser submetido à observação e à experimentação. Partimos, portanto, da hipótese de que homens e mulheres conceptualizavam e categorizavam a violência de forma diferenciada, de acordo com suas experiências de vida. O senso comum parece sugerir que os homens 
relacionam a violência a questões físicas, enquanto as mulheres a relacionam tanto ao aspecto físico quanto ao psicológico. Acreditamos que os homens cearenses, talvez devido ao "machismo" que impera no Ceará, sejam um tanto tendenciosos ao não se reportarem a sofrimentos psíquicos.

Realizamos o estudo em momentos interligados: no primeiro, fizemos uma pesquisa com abordagem qualitativa e procedemos a coleta de dados, por meio de questionários semiestruturados. É válido mencionar que esses questionários foram aplicados somente após a aprovação do Comitê de Ética com Pesquisas com Seres Humanos. Juntamente com o questionário, cada respondente preenchia o termo de Consentimento Livre Esclarecido. Depois dessa fase, por fim, tabulamos e analisamos parte dos dados.

Nossa amostra foi selecionada durante o primeiro semestre de 2013. Escolhemos os sujeitos respondentes dos questionários em função da disponibilidade de colaborar com a coleta de dados, para o estudo posterior.

Como o estudo qualitativo-quantitativo dos cinco mil questionários aplicados pelos bolsistas do CNPq ainda está em fase de conclusão, separamos sessenta questionários de forma aleatória em relação aos sujeitos e de forma controlada em relação ao gênero: trinta de homens e trinta de mulheres.

\section{ANÁLISE E DISCUSSÃO DOS DADOS}

Há dificuldade de conceptualização do fenômeno violência, como já mencionamos. Os aspectos conceituais sobre essa categoria podem ser diferenciados, pois envolvem questões físicas e psicológicas.

Conforme vimos até aqui, o conceito violência configura-se como relativo, difuso e ardiloso, por envolver fenômenos variados da experiência humana.

Vale ainda mostrar algumas definições e conceitos retirados de diversos dicionários sobre o verbete violência, o que de certa forma consolida a relatividade desse conceito. Vejamos algumas definições:

a) violência 1. Nome feminino, 2. Qualidade ou estado do que é violento 3. Força empregada contra o direito natural de outrem 4. Ação em que se faz uso de força bruta; crueldade, 5. Força; intensidade, 6. Veemência, 7. Prepotência; tirania; coação (Do lat. Violentia) (INFOPEDIA, 2003, s/n)

b) violência 1. Qualidade de violento. 2. Ato de violentar. (MINIAURÉLIO 
ESCOLAR, 2007, p. 784)

c) violência 1. Qualidade de violento 2. Ato violento 3. Constrangimento físico ou moral; coação. (ROCHA, 2001, p.698)

Com base nas definições conceituais apresentadas, percebemos, principalmente, a presença do conceito FORÇA em quase todas as acepções de violência mencionadas. Do mesmo modo, observamos que outros conceitos também são tratados como atos de violência, tais como, coação, intensidade, constrangimento, revelando, assim, sobreposições parciais de propriedades entre os conceitos subordinados à violência.

Sob o ponto de vista da Linguística Cognitiva, concordamos com Feltes (2007, p. 260) quando afirma que o conceito de violência deve ser visto como um fenômeno que não é inerente a determinadas ações, mas um "produto de uma determinada experiência biopsicossociocultural” (FELTES, 2007, p. 259), como foi possível perceber nos vários tipos discutidos por Imbusch (2003).

Em outros termos, os modelos cognitivos culturais, que atuam como condições de pano de fundo para as estruturas conceituais, restringem o conceito de violência. Por exemplo, em uma cultura, como a muçulmana se a mulher que comete adultério é apedrejada até a morte, os indivíduos dessa cultura não a entendem como vítima, mas como uma violadora das normas daquela sociedade, devendo, portanto, ser punida. Desse modo, na cultura muçulmana, o pano de fundo preestabelecido não é violado. Porém, se o mesmo acontecesse em nossa sociedade esse ato iria, certamente, ser tratado como um ato de crueldade, logo seria uma violência e uma violação ao nosso pano de fundo cultural.

Podemos inferir que as características das unidades terminológicas, segundo Gonadec (1990, p.3) podem também ser assim compreendidas: "um termo é uma unidade linguística que designa um conceito, um objeto ou um processo. O termo é a unidade de designação de elementos do universo percebido ou concebido. Ele raramente se confunde com a palavra ortográfica sobre seu conteúdo específico".

A Terminologia apresenta vários paradigmas que orientam o seu estudo. Podemos ratificar algumas delas como a Terminologia Clássica ou Terminologia Tradicional (TT), a Teoria Comunicação da Terminologia (TCT), proposta por Cabré, na década de 1990, e a Teoria da Terminologia Sócio-cognitiva ou Socioterminologia de Rita Femmerman (2000). Esses pressupostos são considerados como os mais importantes, porque não tratam dos termos sob o ponto de vista descrito na Teoria 
Geral da Terminologia (TGT) de Wiister, que apresenta caráter prescritivo, ou seja, conduz ao pagamento dos aspectos comunicativos e pragmáticos.

Para efeito de delimitação de nosso aporte teórico, estudaremos o léxico "dor" não somente através dos estudos da Terminologia. Priorizaremos como aporte teórico os estudos sobre cognição, categorização e conceptualização. Esses estudos servirão de base mais sólida para as questões que queremos responder. Vejamos, pois, alguns posicionamentos teóricos sobre esses temas.

Apresentamos um estudo preliminar sobre conceptualização como um processo cognitivo. A abordagem cognitiva na organização do conhecimento resulta da convergência entre a percepção humana, a cognição e as estruturas do conhecimento. Alguns estudiosos desses temas (Gardner, 1996; Jacob; Shaw, 1991; Smith; Russel, 1946 entre outros) consideram os termos conceptualização e categorização como sinônimos. Hoje, há outra perspectiva em que o termo conceito é usado para se referir a uma representação mental de um objeto, ou uma unidade do conhecimento; enquanto, o termo categoria remete à formação dos significados dos conceitos pelas suas associações e similaridades. $O$ foco do nosso estudo ficará na conceptualização. Vejamos, pois, os dados abaixo:

\section{Tabela 1 - Exemplares mais e menos prototípicos de VIOLÊNCIA citados por cearenses}

\begin{tabular}{|l|l|l|l|l|}
\hline \multicolumn{3}{|l|}{ Mais prototípicos } & Menos prototípicos \\
\hline & Mulheres & Homens & Mulheres & Homens \\
\hline 1 & Estupidez & Assalto & Desonestidade & Maldade \\
\hline 2 & Discórdia & Guerra & $\begin{array}{l}\text { Falta de amor à } \\
\text { vida }\end{array}$ & - \\
\hline 3 & Injustiça & Morte & Desumanidade & Descontrole \\
\hline 4 & Mentira & Agressão & Assalto & Racismo \\
\hline 5 & Preconceito & Morte & Brigas & Estupro \\
\hline 6 & Estupro & Violência física & Violência & $\begin{array}{l}\text { Violência } \\
\text { verbal }\end{array}$ \\
\hline 7 & Atitudes violentas & Agressão física & Invasão & - \\
\hline 8 & Morte & Violência física & $\begin{array}{l}\text { Violência ao } \\
\text { idoso }\end{array}$ & $\begin{array}{l}\text { Violência } \\
\text { verbal }\end{array}$ \\
\hline 9 & Violência verbal & Tortura & $\begin{array}{l}\text { Falta } \\
\text { liberdade }\end{array}$ & Violência física \\
\hline 10 & $\begin{array}{l}\text { Desrespeito para } \\
\text { com a pessoa }\end{array}$ & Agressão & Medo & - \\
\hline 11 & Desonestidade & Tráfico de drogas & Falta de saúde & Insegurança \\
\hline 12 & Desconforto & Morte & Drogas & Estupidez \\
\hline 13 & Bullying & Brigar & Atrocidade & Opressão \\
\hline
\end{tabular}




\begin{tabular}{|c|c|c|c|c|}
\hline 14 & Revolta & Violência física & Loucura & Falta de paz \\
\hline 15 & Inimizade & Morte & Precipitação & Bater \\
\hline 16 & Desgraça & Assalto & Sofrimento & Falta de fé \\
\hline 17 & Ignorância & Bater & Abusar & Droga \\
\hline 18 & Falta de respeito & Assalto & Agressão & $\begin{array}{l}\text { Forca } \\
\text { excessiva }\end{array}$ \\
\hline 19 & Violência & Sequestro & Grosseria & $\begin{array}{l}\text { Agressão } \\
\text { verbal }\end{array}$ \\
\hline 20 & Agonia & Estupros & $\begin{array}{l}\text { Stress } \\
\text { momentâneo }\end{array}$ & Agressão \\
\hline 21 & $\begin{array}{l}\text { Descriminação } \\
\text { Aflição }\end{array}$ & & $\begin{array}{l}\text { Grande } \\
\text { tormento }\end{array}$ & $\begin{array}{l}\text { Agressão } \\
\text { psicológica }\end{array}$ \\
\hline 22 & Desejo ardente & Agressividade & Ansiedade & Brutalidade \\
\hline 23 & Agressão verbal & Indução & Preconceito & Opressão \\
\hline 24 & Palavras Feias & Impunidade & $\begin{array}{l}\text { Atitudes } \\
\text { impróprias }\end{array}$ & $\begin{array}{l}\text { Vontade } \\
\text { politica }\end{array}$ \\
\hline 25 & Dor & Estupro & $\begin{array}{l}\text { Desrespeito ao } \\
\text { ser humano }\end{array}$ & Maldade \\
\hline 26 & $\begin{array}{ll}\text { Falta } & \text { de } \\
\text { consciência } & \end{array}$ & Assassinato & - & Sequestro \\
\hline 27 & $\begin{array}{l}\text { Falta de paciência } \\
\text { para conversar }\end{array}$ & Desaforo & Violência Verbal & Inimizade \\
\hline 28 & $\begin{array}{l}\text { Irresponsabilidad } \\
\text { e }\end{array}$ & Amargura & Desumanidade & Angústia \\
\hline 29 & $\begin{array}{l}\text { Violência } \\
\text { doméstica }\end{array}$ & Crime & Violência Física & Agressão \\
\hline 30 & Agressão & Força & Violentar & Crime \\
\hline
\end{tabular}

do estudo mostraram que há diferentes formas de conceptualizar e categorizar a violência. Para cada participante, como sujeito da pesquisa, a categoria VIOLÊNCIA era citada e entendida, muitas vezes, de forma diferente.

No caso de nosso estudo, constatamos que homens e mulheres também diferem quanto à forma de conceptualizar o fenômeno violência. Verificamos que dos 30 homens que participaram desta pesquisa, 18 conceptualizaram violência na esfera física, ou seja, $60 \%$ do total. Por outro lado, menos da metade, ou seja, apenas 12 homens categorizaram a violência como um submodelo de ordem psicológica.

Já com relação às mulheres, das 30 consultadas, apenas 04 conceptualizaram violência no âmbito físico. Ou seja, apenas $13 \%$ entendem violência como um fenômeno físico. O impressionante foi perceber que $86 \%$ dessas mulheres categorizaram a violência como um fenômeno psicológico, em detrimento do físico.

Outro dado interessante foi que 18 homens, dentre os 30 analisados, consideraram como violência, menos prototípica, conceitos ligados à violência não física, como: angústia, inimizade, opressão, agressão psicológica, etc.

Podemos conferir os resultados dos dois grupos no gráfico abaixo: 
Gráfico 1 - Níveis de conceptualização, segundo submodelos físicos e psicológicos entre homens e mulheres cearenses:

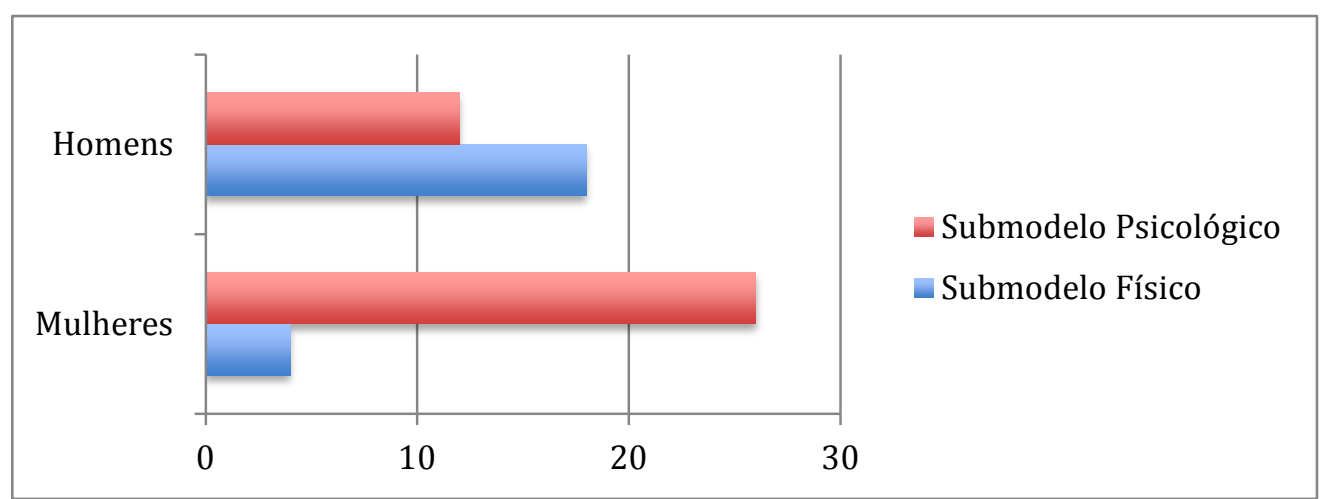

Com base na análise dos dados do Gráfico 1, podemos perceber que os submodelos de ordem física, como bater, estuprar, matar, dentre outros, foram mais recorrentes entre os homens. Dentre as mulheres, a categoria violência foi evidenciada mais acentuadamente enquanto um conceito de ordem psicológica e moral, como desgraça, ignorância, agonia etc.

Logo, pressupomos que, quase sempre, os fenômenos de conceptualização e categorização da violência estão relacionados a situações vividas pelos entrevistados; como por exemplo, violências urbanas - assaltos, sequestros; agressões físicas; agressões morais/verbais e ações relacionadas a tensões por problemas pessoais, ou decepções em relacionamentos humanos.

\section{CONSIDERAÇÕES FINAIS}

Concluímos que efeitos de sentido referentes à categoria VIOLÊNCIA não se apresentam de forma equilibrada entre homens e mulheres cearenses. Em vista disso, confirmamos nossas hipóteses ao constatar que os homens cearenses, devido a viverem em um meio social no qual o homem precisa ser "macho" e forte, apresentaram conceitos de violência consoantes com esse modo de agir no mundo. Ou seja, no grupo de homens, o exemplar mais saliente constituiu o submodelo metonímico de FORÇA FÍSICA. Já o grupo feminino apresentou exemplares que se enquadravam no submodelo metonímico de FORÇA PSICOLÓGICA. Em suma, ratificamos que a categoria violência é, de fato, produto de uma determinada experiência biopsicossociocultural, cujos conceitos sofrem restrições cognitivoculturais não tendo, portanto, caráter universal. 


\title{
NOTAS
}

${ }^{1}$ Cursando o Doutorado de Linguística da UFC, Coordenadora do Curso de Extensão em Inglês da UECE.

2 Professora Adjunta da UECE e do Programa de Pós-Graduação em Linguística Aplicada da UECE/ Pró-Reitora de Pós-Graduação, Pesquisa e Extensão do Centro Universitário Estácio do Ceará.

\section{VIOLENCE: A CATEGORIZATION OF MEN AND WOMEN FROM CEARÁ}

\begin{abstract}
Violence can be considered one of the most elusive and difficult concepts to be defined within the social sciences and perceive themselves little discussion from the point of view of language. In our work, we find the way of structuring the category VIOLENCE, as well as the scales of prototypicality from specimens mentioned by men and women of Ceará. Thus, based on the Theory of Categorization Rosch (1970) and Theory of prototypes Lakoff (1987), had the objective of determining if there were significant differences between the scales of category prototypicality that had been identified in two distinct groups: of men and women Ceará. We adopt, as a theoretical, postulates Rosch, Gray and Boyes-Braem (1976a), Lakoff (1987), Eysenck and Keane (1994), Medin and Ross (1996), Jacob and Shaw (1998) among others. We note that the specimens cited by women and men, in the questionnaires to define the category VIOLENCE if presented differently, confirming one of our hypotheses: the man Ceará is considered "goat plague", macho man, which makes more evident the physical than psychological. The results revealed that while the group of men the most salient example was the submodel metonymic PHYSICAL FORCE, the females had specimens that were included on submodel metonymic PSYCHOLOGICAL FORCE.
\end{abstract}

Keywords: Violence. Categorization. Prototypicality. Genres. 


\section{REFERÊNCIAS}

EVANS, V.; GREEN, M. Cognitive linguistics: an introduction. Edinburgh: Edinburgh University Press, 2006.

FELTES, H. P. M. Semântica cognitiva: ilhas, pontes e teias. Porto Alegre: EDIPUCRS, 2007.

FERREIRA, A. B. H. Novo dicionário da língua portuguesa. Rio de Janeiro: Nova Fronteira, 1986.

INFOPEDIA ENCICLOPÉDIA E DICIONÁRIOS. Porto, 2003. Disponível em: <http://www.infopedia.pt/>. Acesso em: 5 de mar. 2011.

IMBUSCH, P. The concept of violence. In: HEITMEYER, W.; HAGAN, J. (Ed. ). International handbook of violence research. Netherlands: Kluer Academic Publishers, 2003. p. 13-40.

JAMISON, K.G. Quem casa quer casa: a conceitualização e categorização de violência por mulheres vítimas de violência conjugal. 201. Dissertação (Mestrado em Linguística Aplicada)-Universidade Estadual do Ceará, Fortaleza, 2011.

LAKOFF, G. Women fire and dangerous things: what categories reveal about the mind. Chicago: The University of Chicago Press, 1987.

LIMA, G.A.B. Categorização como um processo cognitivo. Ciências e Cognição. 2007. v. 11. p. 156-167. Disponível em:

<http://www.cienciasecognicao.tempsite.ws/revista/index.php/cec/article/.../663/444>. Acesso em: 14 set. 2013.

MACEDO, A.C.P.; FELTES, H.P. de M; FARIAS, E.M.P. Cognição e linguística: mapeando territórios, domínios e percursos. Caxias do Sul, RS: EDUCS, 2008.

MINI AURÉLIO ESCOLAR: o dicionário da língua portuguesa. Curitiba: Positivo, 2007.

MURPHY, G. The big book of concepts. 2. ed. Cambridge: MIT Press, 2004.

ROCHA, R. Minidicionário Ruth Rocha. São Paulo: Scipione, 2001.

ROSCH, E. Cognitive Reference Points. Cognitive Psychology, [S.I], v. 7, p. 532-547, 1975.

ROSCH, E.; SIMPSON, C.; MILLER, R. S. Structural bases of typicality effects. Berkeley: University of California, 1976.

TEMMERMAN, R. Towards new ways of terminology description: the sociocognitive approach. Amsterdam/Philadelphia: John Benjamins, 2000. 
SMITH, E.; MEDIN, D.L. Categories and concepts. Cambridge, Massachusetts: Harvard University Press, 1981.

VARELA, F.; THOMPSON, E. ; ROCH, E. A mente corpórea: ciência cognitiva e experiência humana. Lisboa: Instituto Piaget, 2003.

1998.

. As ciências cognitivas: tendências e perspectivas. Lisboa: Instituto Piaget, 